\title{
Complex treatment after pathohistological and immunohistochemical analysis in synchronous neoplasms - anorectal achromatic malignant melanoma and gastric extrapleural solitary fibrous tumor
}

\author{
Lena Marinova $^{1 *}$, Bistra Yordanova ${ }^{2}$, Nikolay Evgeniev ${ }^{3}$ and Kremena Petrova ${ }^{1}$ \\ ${ }^{1}$ Department of Radiotherapy, Complex Oncology Center - Ruse, Bulgaria \\ ${ }^{2}$ Department of Clinical Pathology, Complex Oncology Center - Ruse, Bulgaria \\ ${ }^{3}$ Medical Oncology Department, Complex Oncology Center - Ruse, Bulgaria
}

\begin{abstract}
A 76-year-old woman diagnosed with extremely rarelysynchronous neoplasms - rectal malignant melanoma (RMM) and a benign variant of gastric extrapleural solitary fibrous tumor (GESFT) is presented. Against the background of a literature review, the pathomorphological characteristic, the necessary immunohistochemical panel and the difficult differential diagnosis with the wide range of benign and malignant mesenchymal tumors are discussed. The necessary complex oncological treatment, directly depending on the prognostic risk factors for each of these synchronous tumors is analyzed.

For the first time in the English medical literature, a clinical case with synchronous tumors - rectal achromatic malignant melanoma and gastric solitary fibrous tumor is presented.

After complex treatment, including surgery and adjuvant radiotherapy of the RMM and surgery of the gastric tumor, we report a one-year disease-free survival with a good quality of life.
\end{abstract}

\section{Introduction}

Anorectal malignant melanoma (ARMM) is an extremely rare and very aggressive disease with a very poor prognosis [1-5]. This highly malignant entity constitutes only $0.5-4 \%$ of all anorectal malignancies and less than $1 \%$ of all melanomas [6,7]. The first description of ARMM in the literature dates from 1897, by Moore [8]. Amelanotic lesions are frequent in mucosal melanoma [9]. The incidence is difficult to calculate because several authors indicate amelanotic melanomas those only partially devoid pigment at visual inspection [10,11]. Solitary fibrous tumor (SFT) is a rare neoplasm, first described as a pleural formation in 1931 by Klemperer et al. [12]. Subsequently, it was found that SFT is localized not only in the intrathoracic organs and structures, but also in extrapleural areas, involving soft tissues and parenchymal organs [13]. SFTs make up $<2 \%$ of all soft tissue tumors [14,15]. Gastric localization of SFTs is a very rare disease, which by 2018 was published in seven patients, one of whom with pronounced pathohistological dedifferentiation [15]. For the first time in the English medical literature, a clinical case with synchronous tumors - rectal achromatic malignant melanoma and gastric solitary fibrous tumor is presented.

\section{Clinical case}

We present a 76-year-old patient with symptoms including diarrheal syndrome and periodic rectorrhea with anal pain. The diagnosis was made in October 2019 after rectocolonoscopy with biopsy. In January 2020, after immunohistochemical analysis of the biopsy material, an operation, including extirpation of the rectum a modo Miles with simultaneous partial resection of the stomach was performed.

From the examinations: Rectocolonoscopy: Approx. $4 \mathrm{~cm}$ from the anorectal line, a tumor process on the posterior wall, ulcerated and easily bleeding to the touch was found. A biopsy for histological verification was taken.

CT of the thorax and abdomen: Lung, mediastinum, liver, gallbladder, pancreas, spleen, adrenal glands, kidneys - without pathology observations; There are no pathologically enlarged paraaortic, pelvic and inguinal lymph nodes. Small pelvis:

Rectum - Near the sphincter along the lateromedial contour on the left, there is a reinforcing intraluminal formation. Free perirectal adipose tissue, no visible changes.

Stomach- In the middle third, along the greater curvature, there is an intramural lesion measuring $35 / 24 \mathrm{~mm}$, with calcification on

*Correspondence to: Lena Marinova, Department of Radiotherapy, Complex Oncology Center - Ruse, Bulgaria, E-mail: rad_marinova@abv.bg

Key words: anorectal achromatic malignant melanoma, gastric extrapleural solitary fibrous tumor, pathohistology, immunohistochemistry, surgery, radiotherapy, chemotherapy

Received: September 11, 2020; Accepted: September 24, 2020; Published: September 30, 2020 
Marinova L (2020) Complex treatment after pathohistological and immunohistochemical analysis in synchronous neoplasms - anorectal achromatic malignant melanoma and gastric extrapleural solitary fibrous tumor

the upper surface, a solid component in the lateral part, as well as a hypokinetic area near the mucosa. Macroscopically, the gastric tumor resembles GIST.

Intraoperatively: After mid-xyphopubic laparotomy, in the distal part of the large curvature of the stomach, an intramural tumor $4 \mathrm{~cm}$ in diameter with a macroscopic GIST was found. Partial resection of the stomach with removal of $2 \mathrm{~cm}$ of healthy tissue surrounding the tumor was performed. Liver metastases and enlarged paraaortic lymph nodes were not detected. On the posterior wall of the rectum, $3 \mathrm{~cm}$ proximal to the anus, a tumor formation was found. Sigma and rectum were dissected and total mesorectal excision with abdomino-perineal extirpation of the rectum modo Miles was performed.

Histological diagnosis: Macroscopic description: 1) Resect of the colon (recto-anal area) with a length of $35 \mathrm{~cm}$. In the area of the rectum at the level of the anorectal line a nodular tumor $6 \mathrm{~cm}$ in diameter is found, with lobulated surface, inhomogeneous brown color and hemorrhage. When cut macroscopically, the tumor does not pass into the surrounding soft tissues. The tumor is $3.5 \mathrm{~cm}$ from the outside of the anus. ; 2) Part of the stomach $6 / 4.5 \mathrm{~cm}$. A submucosal incision reveals a nodule with a gelatinous consistency with a diameter of 2.5 $\mathrm{cm}$. Areas with calcifications and cartilage density are established.

\section{Microscopic description}

The tumor of the rectum is represented by solid nodules of the same type of cells with sparse cytoplasm and large round nuclei with mostly peripherally located chromatin and large nucleoli. The cells are closely spaced, with no distinct stroma between them, only the presence of capillaries in places. In some areas there are hemorrhages and intercellular edema, giving discohesion to the cells. No pigment is found. Cell growth is reported among the colon glands, enclosing them without destroying them, thus some of the glands are atrophic and others are dilated and filled with mucus. There is mitotic activity. The tumor engages the mucosa and submucosa with ulceration (Figures 1A and 1B); Resection line - free of tumor cells; Anus - acanthosis and papillomatosis of the epidermis; free of tumor cells; Regional lymph nodes/12 pieces/without metastases, with sinus histiocytosis.

Soft tissue tumor of the stomach, located submucosally with the involvement of the tunica muscularis. It consists of randomly arranged cells of different types: those with round nuclei, others with small elongated nuclei and others with morphology of single and multilocular lipoblasts with low mitotic activity (Figures 2A, 2B and 3).

\section{Immunohistochemistry (IHC)}

From the rectal tumor: Diffuse positive IHC expression in tumor cells for HMB 45; S100 protein; Melan A (Figure 4).

From a gastric tumor: Diffuse positive CD34 reaction in tumor cells and tumor blood vessels and adjacent gastric wall (Figure 5A and $5 \mathrm{~B}$ ) and focal positive $\mathrm{S} 100$ protein expression in part of tumor cells (Figure 5C).

Negative reaction for CK AE1-AE3 in tumor cells, but positive expression in normal gastric epithelium adjacent (Figure 6A); Negative reaction for SMA and Desmin in tumor cells, but positive in blood vessels (Figure 6B and 6C); Negative reaction for Myogenin (Figure 6D).

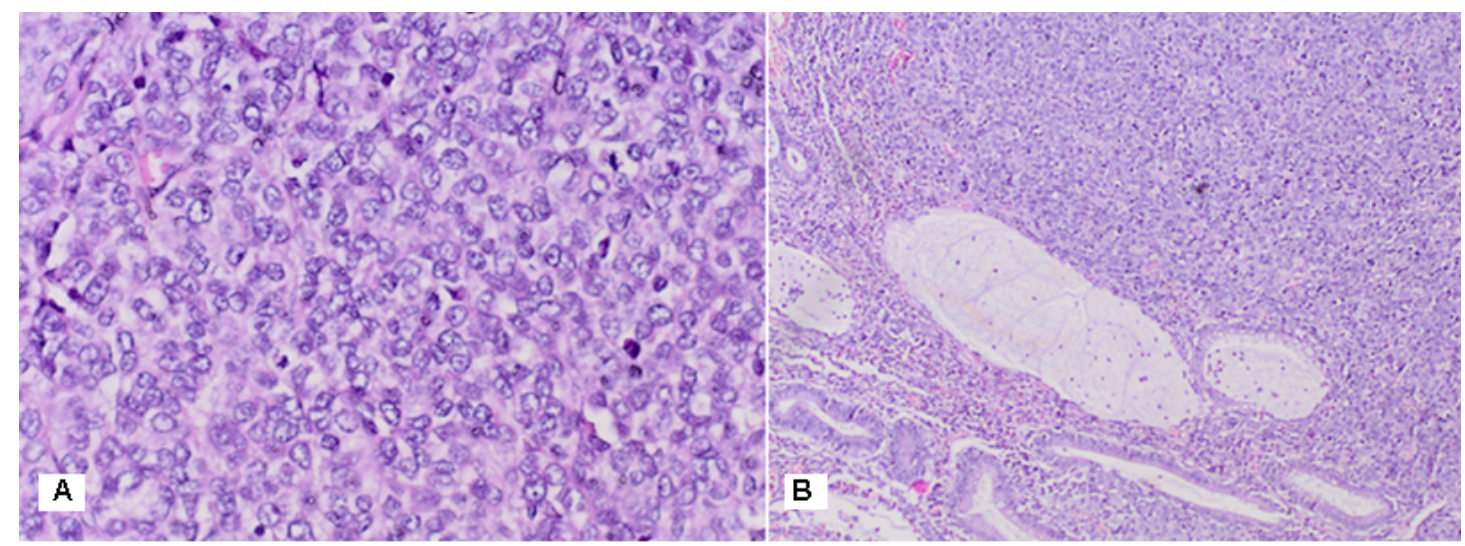

Figure 1. Pathohistological characteristics of rectal achromatic malignant melanoma: A) H \& E x 40; B) H \& E x 20

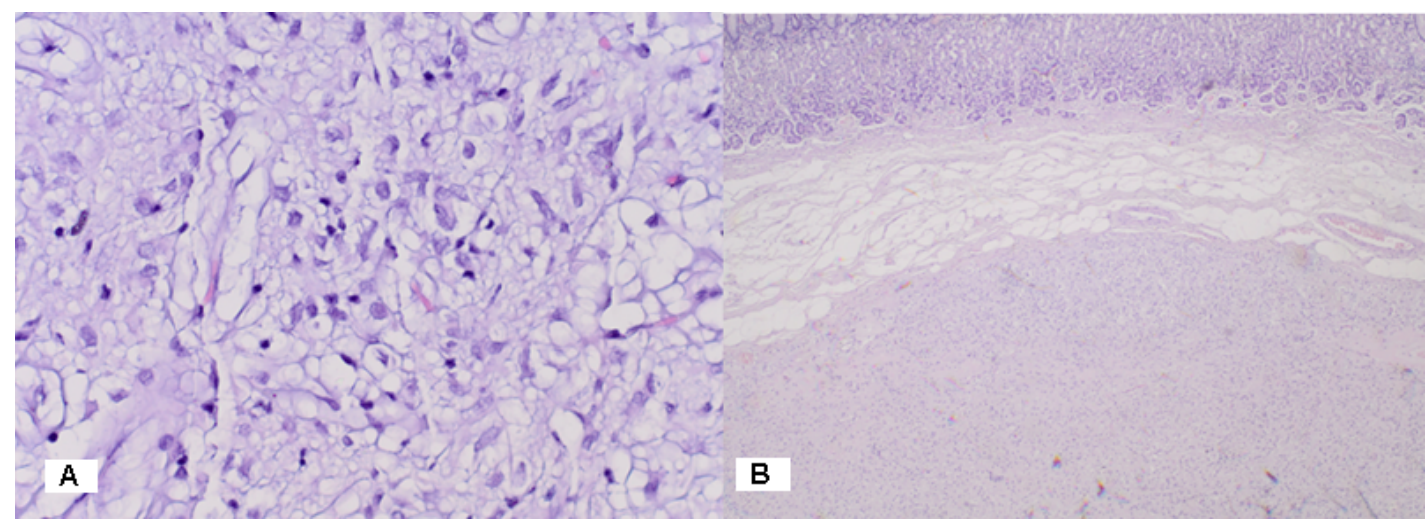

Figure 2. Pathohistological characteristics of gastric solitary fibrous tumor: A) H \& E x 40; B) H \& E x 4 
Marinova L (2020) Complex treatment after pathohistological and immunohistochemical analysis in synchronous neoplasms - anorectal achromatic malignant melanoma and gastric extrapleural solitary fibrous tumor

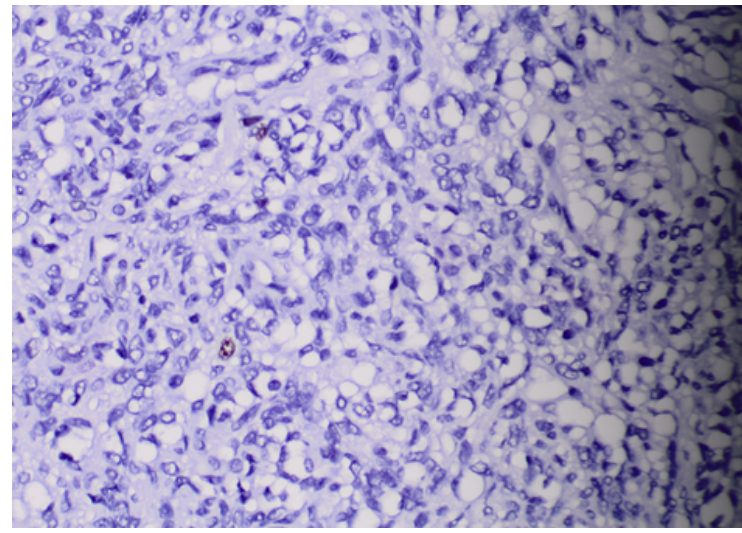

Figure 3. Photomicrography of Ki 67 IHC expression: Low mitotic activity $1 \%-2 \% \times 40$

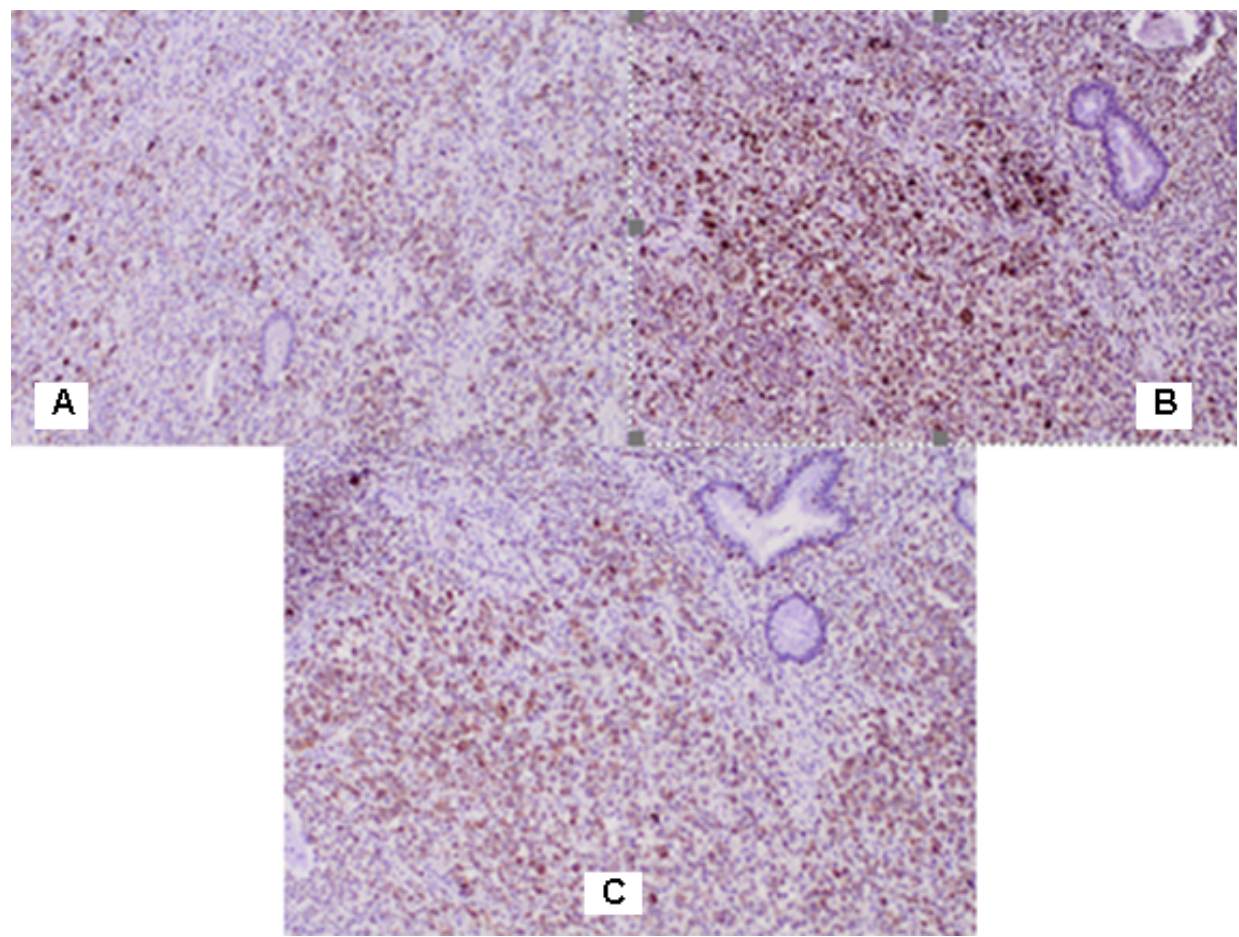

Figure 4. Photomicrography of positive diffuse IHC expression in tumour cells in anorectal malignant melanoma: A) HMB 45 x 20; B) S100 protein x 20; C) Melan A x 20

\section{Histological diagnosis}

1) After IHC: Achromatic malignant melanoma of the rectum - small cell variant pT3pN0Mx G3/ Stage II; 2) After IHC: Benign variant of gastric solitary fibrous tumor

Postoperatively, adjuvant intensively modulated radiotherapy (IMRT) with VMAT technique in the anorectal tumor bed up to total dose (TD) 56 Gy and in the pelvic lymph nodes bilaterally up to TD 54 Gy with a daily dose (DD) 2 Gy was performed (Figure 7).

To assess the need for therapy with BRAF inhibitors or MEK inhibitors, a molecular biological analysis for mutations in codon 600 BRAF, that were missing was performed. The patient was assessed for dispensary observation. During September 2020, on the control CT examination with intravenous contrast of the thorax, abdominal organs and small pelvis - no pathological changes are found. After one year from the diagnosis of synchronous tumors, the patient is without local recurrence and distant metastases, in good quality of life.

\section{Discussion}

All melanomas, whether cutaneous or mucosal in origin, originate from melanocytes, which are cells derived from the embryological neural crest [1]. The rectum has a typically glandular epithelium. On the other hand, the anal canal, below the pectineal line, is covered by a squamous epithelium [16]. Right above the pectineal line is the transition zone, where both glandular and squamous cells are present. Melanocytes may appear in the three regions (rectum, anal canal and transition zone), although the occurrence of melanoma is more frequent in the transition zone and squamous epithelium [17-24]. A timely diagnosis of anal melanoma is made even more difficult by the fact that up to $80 \%$ of lesions lack obvious pigmentation and up 
Marinova L (2020) Complex treatment after pathohistological and immunohistochemical analysis in synchronous neoplasms - anorectal achromatic malignant melanoma and gastric extrapleural solitary fibrous tumor

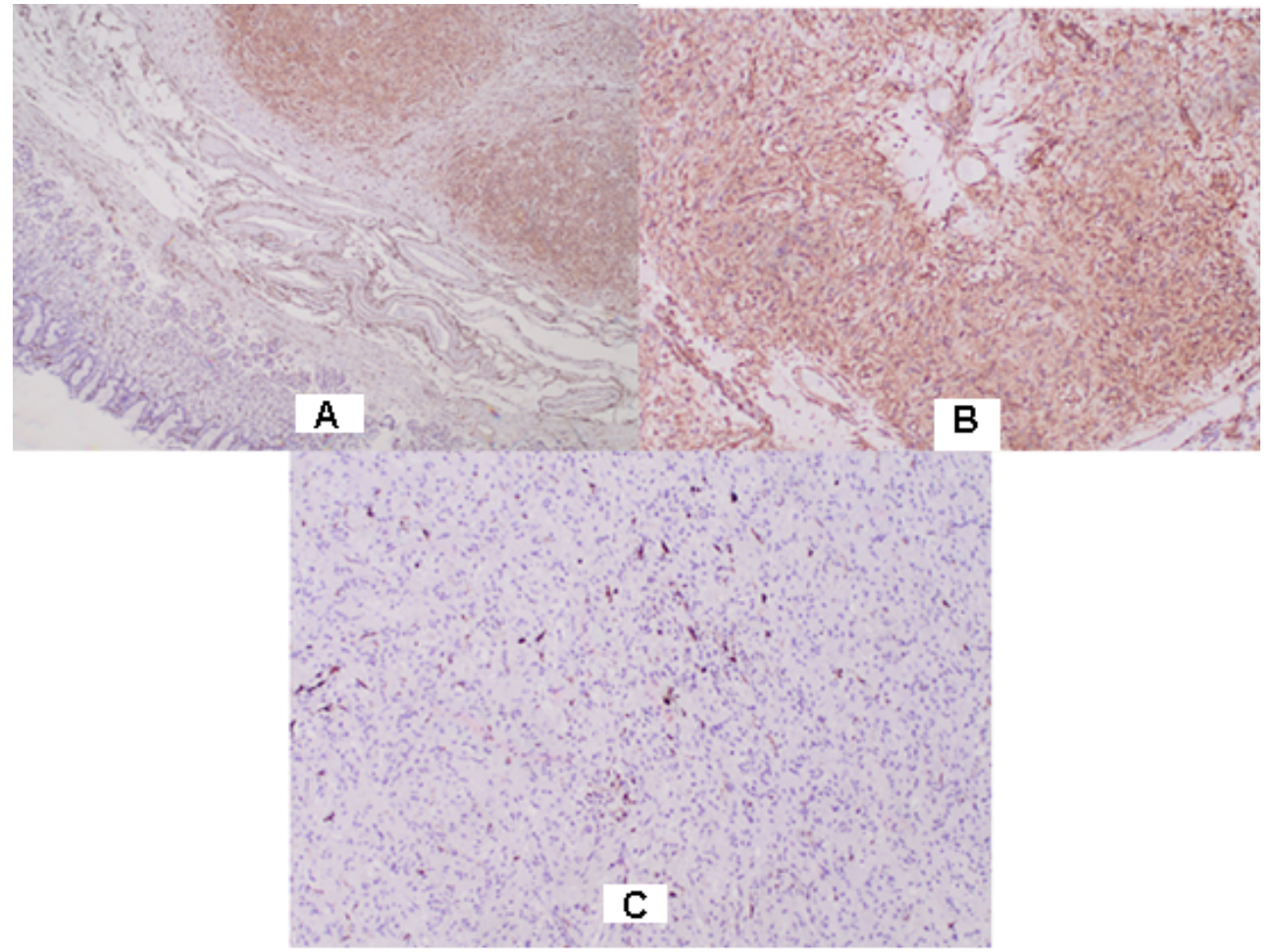

Figure 5. Photomicrography of positive IHC expression in gastric solitary fibrous tumor: A) CD 34 x 4; B) CD 34 x 20 ; C) S100 protein $\times 20$

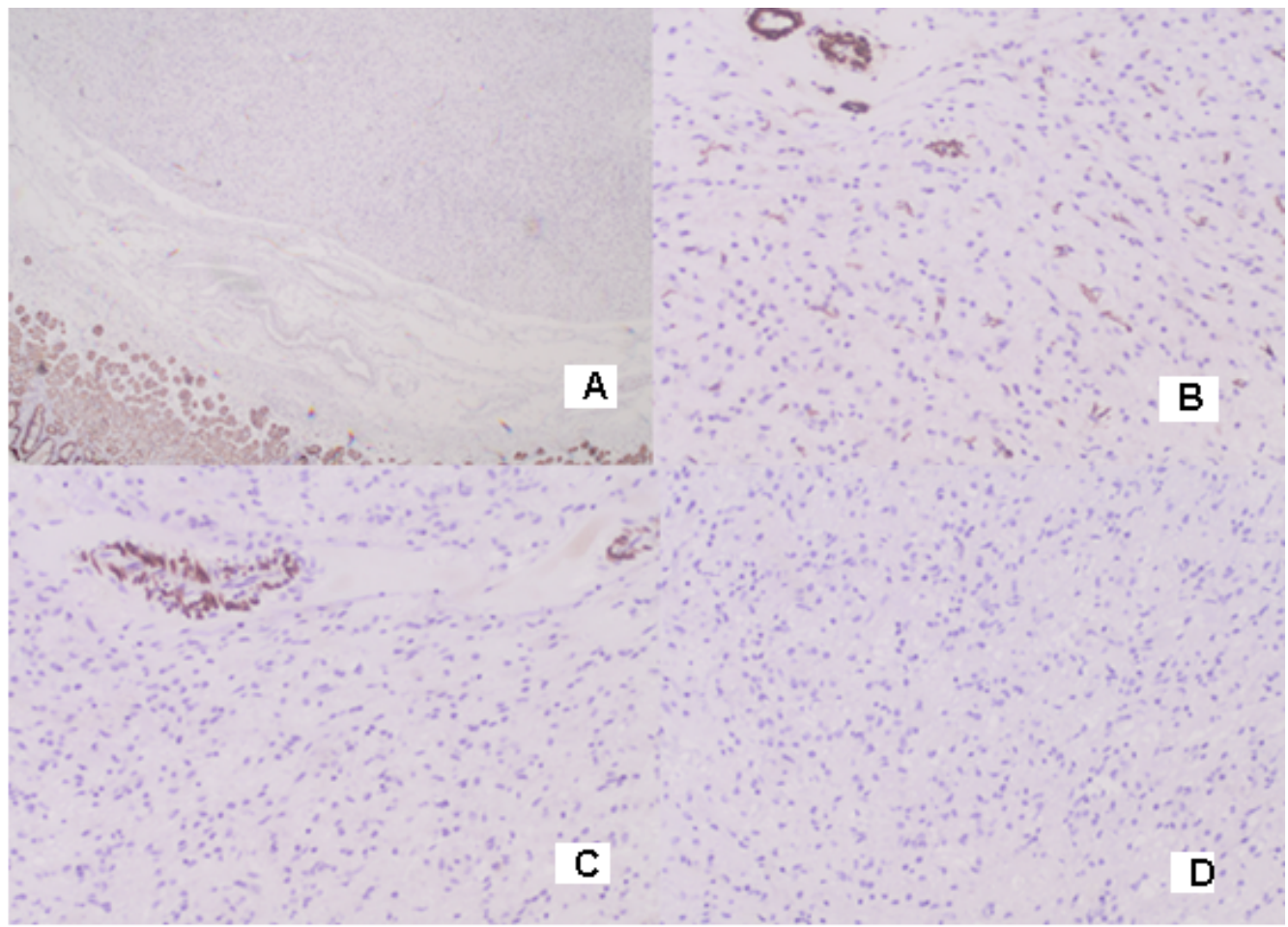

Figure 6. Photomicrography of IHC expression in gastric solitary fibrous tumor: A) Negative reaction for CK AE1-AE3 in tumor cells, but positive expression in normal gastric epithelium adjacent x4, B) Negative reaction for SMA in tumor cells, but positive in blood vessels x 20; C) Negative reaction for Desmin in tumor cells, but positive in blood vessels x20; D) Negative reaction for Myogenin x 20 
Marinova L (2020) Complex treatment after pathohistological and immunohistochemical analysis in synchronous neoplasms - anorectal achromatic malignant melanoma and gastric extrapleural solitary fibrous tumor
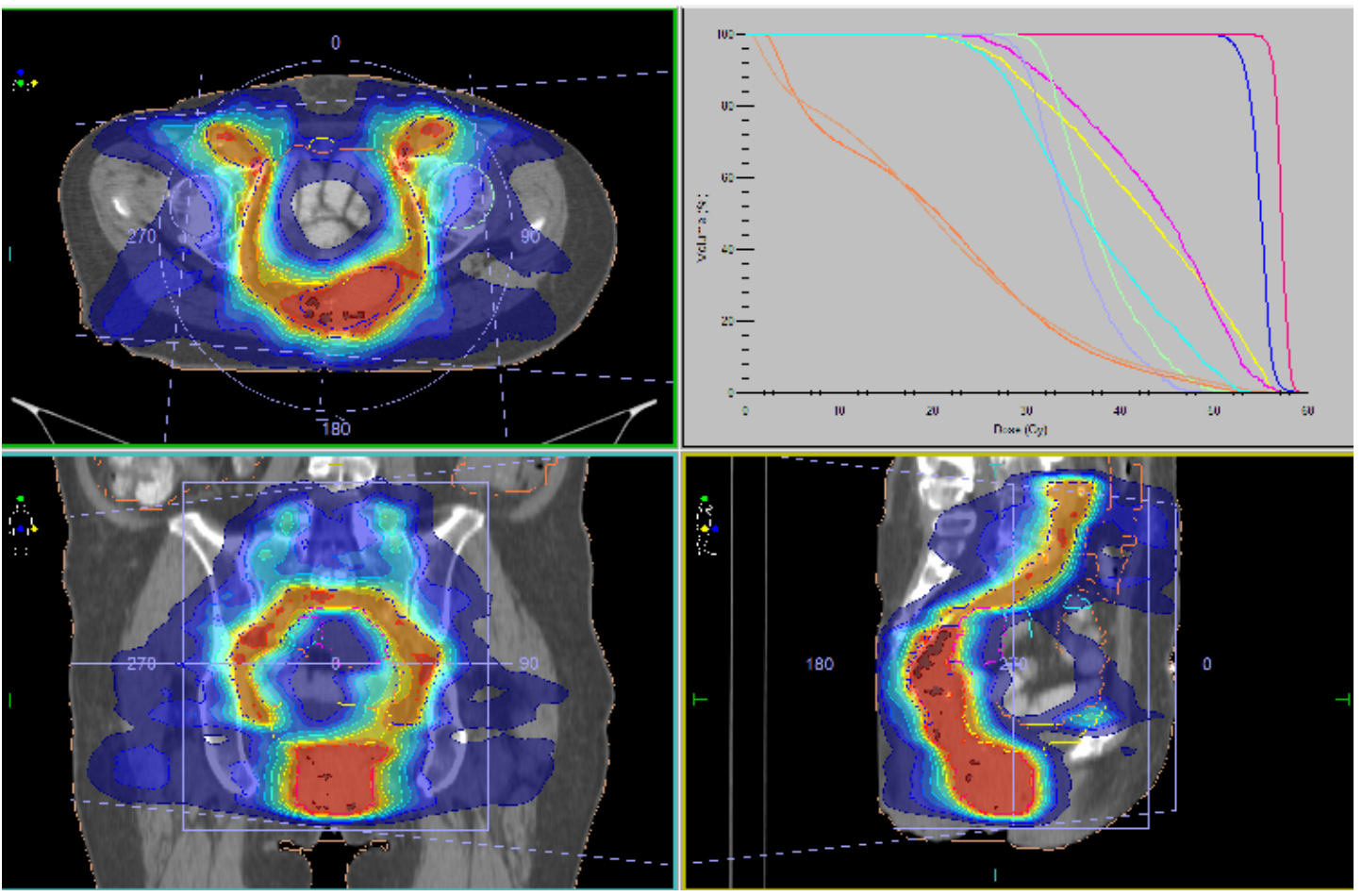

Figure 7. Adjuvant IMRT with VMAT technique in the anorectal tumor bed up to TD 56 Gy and in the bilaterally pelvic lymph nodes up to TD 54 Gy with DD 2 Gy

to $20 \%$ of tumors are even histologically amelanotic [25,26]. ARMM is often misdiagnosed in about two thirds of patients and most often as haemorrhoids, adenocarcinoma polyps and rectal cancer [27]. Anal melanoma is staged on a clinical basis, focusing on loco-regional and distant spread. Stage I is local disease only, Stage II is a local disease with increased thickness and ulcerations, Stage III is local disease with involvement of regional lymph nodes, and Stage IV shows distant metastatic disease $[6,28]$.

\section{Pathohistological characteristics}

Macroscopically observed single or multiple, large polypoid mass, $80 \%$ pigmented, grows near dentate line [29]. The pathohistological microscopic characteristic is identical to cutaneous melanomas with the following cellular patterns: epithelioid; spindle cell; lymphomalike and pleomorphic [30,31]. Melanoma cells are larger than normal melanocytes, with large and irregular nuclei, well or poorly clustered into nests (Figure 1). The higher the number of mitoses, the worse the diagnosis [16].

\section{Immunohistochemistry (IHC)}

ARMM is characterized by positive IHC expression to HMB45, S100, Melan A $[1,16,17,30]$ and negative to Keratin [30]. In Figure 4, we report diffuse positive expression of tumor cells to HMB45, S100, Melan A.

\section{Differential diagnosis (DD)}

Differential diagnosis is required with some diseases such as as Paget, Bowen, lymphomas, undifferentiated carcinomas, sarcomas and gastrointestinal stromal tumor (GIST) $[29,31,32]$. It is achieved by strict immunohistohistochemical analysis. Thus, especially in amelanic ARMs (but also in melanocytic ones), immunohistochemistry should be performed - the study of protein expressions of melanocytes [32].

\section{Complex treatment}

The surgical treatment with curative intent should be proposed, considering the disease stage and the clinical conditions of each patient [17]. Most frequent approaches include: Abdominoperineal Amputation (APA) and Wide Local Excision (WLE). For a long time, the APA was considered the standard therapy, but several studies have demonstrated no significant difference in survival when comparing it to more conservative approaches (APAversus WLE) [17-24,33]. APA should be performed in case of larger tumors, recurrences, disease with locoregional invasion or when a good local control is required [16]. Despite the treatment options and attempts, the prognosis remains guarded, with survival rates in five years as low as $6 \%$ and mean survival of 25 months [17-24,34], regardless of the treatment type [35,36]. Radiotherapy (RT) and chemotherapy (Ch) are considered ineffective for treatment of ARM. Some authors who have used RT-Ch reported that they did not observe any advantage $[37,38]$. One of the subgroups of ARM, with mutations in the BRAF gene, respond to the action of BRAF inhibitors (PLX4032 and RAF265), leading to regression of disease in up to $70 \%$ of patients with metastatic melanoma with BRAF V600E mutation [39]. The medications used in adjuvant therapy are cisplatin, vinblastine, dacarbazine, interferon B, and Interleukins IL2. Dacarbazine is the most commonly used single agent and usually initiates a partial response in $20 \%$ of patients in $4-6$ months after treatment $[6,28]$.

Solitary fibrous tumors (SFT) are uncommon fibroblastic mesenchymal neoplasms estimated to account for $<2 \%$ of all soft tissue neoplasms and occur typically in the fifth or sixth decade [40]. Since then, nonpleural SFTs have been described as originating from almost every anatomic location of the human body, but reports of SFTs in the abdominal cavity are rare [41]. Little is known about the natural history and malignant potential of these; however the literature suggests that the majority (78-88\%) are histologically benign [42]. There were only 
Marinova L (2020) Complex treatment after pathohistological and immunohistochemical analysis in synchronous neoplasms - anorectal achromatic malignant melanoma and gastric extrapleural solitary fibrous tumor

six SFT cases arising from the stomach reported in the literature with none having features of dedifferentiation and early metastatic spread to liver [43-44].

Pathohistological diagnosis is often difficult due to the rare incidence of SFT and the wide range of benign and malignant mesenchymal tumors. Soft tissue tumors with hemangiopericytoma (HPC) - resembling a growth model are divided into three categories: 1 ) solitary-fibrous tumor group with histological variants; 2 ) lesions with clear evidence of myoid/pericyte differentiation and the corresponding "true" HPC (Myopericytoma/glomangiopericytoma and the subgroup of the sinonasal HPC; 3/ neoplasms that occasionally show HPClike functions (synovial sarcoma) $[45,46]$. SFTs are neoplasms, often showing a hemangiopericytoma-like vascular arrangement pattern. Macroscopic, histological and IXX analysis are crucial for diagnosis [47]. Macroscopically, most of the SFT are encapsulated and rounded, sometimes lobulated with a homogeneous density. The tumor may be large, with a yellowish-brown cut surface, and in the presence of fatty differentiation (lipomatous variant), myxoid and hemorrhagic changes may be observed [48-53]. Tumor necrosis and capsular invasion are criteria for aggressive and malignant tumors (10\% of cases) $[48,51,52]$.

The cytological characteristics of SFT include 1) round to oval moderately atypical cells; 2) increased finely granulated chromatin; 3) absence or presence of barely noticeable nucleoli; 4) background of irregular collagen fragments; 5) scarce and unclear cellular cytoplasm [54-56]. Morphologically, it is difficult to distinguish benign from malignant SFT. Tumor cell polymorphism and dyskaryosis are cytological features of a malignant tumor. In general, benign SFTs do not contain a nucleus [57].

Pathohistologically SFT are presented mainly by the absence of a specific cellular pattern of distribution [58], characterized by a combination of hypo- and hypercellular proliferation of oval or spindle-shaped cells, areas separated by hyalinized fibrous bundles and the presence of elongated and dilated vessels and often hyalinized walls or multiple thin-walled blood vessels with a deer antler-like configuration $[59,60]$, i.e., hemangiopericytic-like vascular branches. Our observations from the gastric solid fibrous tumor take into account the randomly arranged cells of different types: some of the cells have rounded nuclei, others with drained nuclei and others with morphology of uni- and multilocular lipoblasts with low mitotic activity (Figures 2A, 2B and 3). Cellular atypia is not seen in benign STFs. Mitotic figures are rare, no necrosis, hemorrhage or vascular invasion [46]. Atypical tumors present by cells containing sparse cytoplasm with unclear borders and dispersed chromatin in vesicular nuclei. Mitoses are scarce, rarely 3 mitoses on a pallet with an increase of 10 . Some SFTs may contain in separate areas mature adipose tissue and/or multinucleated giant stromal cells, overlapping with the so-called lipomatous hemangiopericytomas and giant cell angiofibromas [47]. The malignant variant of SFT usually consists of hypercellular lesions showing at least focal-moderate cytological atypia, tumor necrosis, multiple mitoses/more than 4 mitoses of the field with an increase of 10 and capsular invasion $[48,51,52]$. Rare myxoid SFTs can create a problem with the differential diagnosis (DD) of much more aggressive neoplasms or soft tissue tumors with other differentiation. Branches and dilated blood vessels typical of SFT, known as hemangiopericytoma-like vessels, may be a feature of several other malignant soft tissue tumors (synovial sarcomas or peripheral neural malignancies), indicating that pathohistological DD should be considered. a wide range of other soft tissue neoplasms [59]. The so-called "growth pattern without a model" or a combination of different histological features such as fascicular, neural, and diffuse sclerosing can lead to a misdiagnosis [61].

\section{Immunohistochemistry (IHC)}

In SFT with different organ localization, no histological and IHC difference is reported [54,62-65]. CD34 antigen, which is a transmembrane glycoprotein, helps in the diagnosis of SFT $[43,44]$, as it is highly positive in $90 \%-95 \%$ of patients $[45,47-50,52,66-76]$. In the presented clinical case, strong diffuse expression to CD34 was reported (Figures 5A and 5B). Tumor cells show high expression to CD99 in $60-70 \%$ of cases $[47,59,67,70,72]$. In $20 \%$ to $35 \%$, variable positivity to EMA and B-cell lymphoma 2 (BCL-2) was observed in $30 \%-50 \%$; as well as less frequently to SMA $[47,51,52,66,69,70,77]$. Focal or limited reactivity was reported for S- 100 protein $[51,52,66,69,72]$ (Figure 5C). Spindle cells are positive for Vimentin [68]. Tumor cells are negative for Cytokeratin [67-69,72]. Pancytokeratin, CD117 (c-kit), Desmin [69] and Factor VIII [59]. High levels of expression to progesterone receptors are possible [73]. In the presented clinical case we report negative reaction for CK AE1-AE3 in tumor cells, but positive expression in normal gastric epithelium adjacent (Figure 6A); negative reaction for SMA and Desmin in tumor cells, but positive in blood vessels (Figure 6B and 6C); and negative reaction for Myogenin (Figure 6D). In the presented clinical case we report low cellular mitotic activity of $1 \%-2 \%$, which determines the benign nature of SFT (Figure 3).

\section{Differential diagnosis (DD)}

SFT may resemble other tumors, so DD is based primarily on ICH to CD34, Vimentin, and CD99 [78]. DD includes a number of benign lesions, such as leiomyoma, schwannoma, benign fibrous histiocytoma to malignant lesions such as well-differentiated fibromyxoid sarcoma, malignant tumor of the peripheral nerve sheath, and malignant fibrous histiocyte, which necessitates ICH $[46,47]$. The differential diagnosis of gastric SFT includes gastrointestinal stromal tumor, calcifying fibrous tumor, fibromatosis, schwannoma, leiomyoma, leiomyosarcoma, inflammatory myofibroblastic tumor, fibrosarcoma, malignant fibrous histiocytoma, hemangiopericytoma, synovial sarcoma, and malignant mesenchymoma [41-80]. Differentiation from highly malignant sarcomas, benign and malignant fibrous histiocytes, as well as desmoid tumors is due to their negative expression to CD34 [59,81]. Monophasic synovial sarcoma is evidenced by a uniform cell growth pattern and ICH focal expression to Keratin $[75,82,83]$. Neurofibroma and peripheral nerve sheath malignancy show different expression to CD34 and bcl-2, but SFTs are strongly positive for these markers [81].

\section{Criteria for malignancy}

The general criteria for malignant SFT with aggressive biological development include: 1/increased number of cells /accumulation of many cells; 2 / moderately atypical cells; 3 / high degree of mitosis/4 in a field with a magnification of $10 ; 4 /$ invasion and/or necrosis $[66,72,84]$. In atypical or malignant tumor variants, visibly increased cellularity, cellular atypia (nuclear pleomorphism, nuclear hyperchromasia), increased mitotic index, and tumor necrosis have been reported [69].

\section{Complex treatment}

The main treatment for SFT is surgery. Surgical management of SFTs is similar to most soft tissue sarcomas with a goal of wide resection margins and preservation of any critical surrounding organs or other structures. Obtaining adequate negative margins has been shown to decrease the rate local disease recurrence and improve survival [85]. Several case series have demonstrated complete resection to be associated with low rates of local recurrence and progression to metastatic disease [86]. Positive margins, tumors size greater than $10 \mathrm{~cm}$ or malignant histology, are risk factors for local failure for extra-pleural 
Marinova L (2020) Complex treatment after pathohistological and immunohistochemical analysis in synchronous neoplasms - anorectal achromatic malignant melanoma and gastric extrapleural solitary fibrous tumor

SFTs [87]. The addition of adjuvant radiotherapy has been reported in select cases, when there is incomplete resection of the tumor especially for the malignant variety [88]. Similar to SFT of the pleura, systemic therapy with ifosfamide or doxorubicin may be considered in recurrent cases or those that show malignant features [89].

\section{Conclusion}

Anorectal malignant melanoma is an extremely rare and aggressive disease which is associated with a poor prognosis. Gastric localization of SFTs is a very rare disease, which by 2018 was published in seven patients. For the first time in the English medical literature, a clinical case with synchronous tumors - rectal achromatic malignant melanoma and gastric solitary fibrous tumor is presented. The article emphasizes the importance of pathohistological and immunohistochemical analysis for the correct oncological diagnosis and differential diagnosis. We report a one-year disease-free survival with a good quality of life after complex treatment, including surgery and adjuvant radiotherapy of the rectal achromatic malignant melanoma and surgery of the benign gastric tumor.

\section{References}

1. Kohli S, Narang S, Singhal A, et al. (2014) Malignant melanoma of the rectum. J Clin Imaging Sci 4: 4.

2. van Schaik PM, Ernst MF, Meijer HA, Bosscha K (2008) Melanoma of the rectum: A rare entity. World J Gastroenterol 14: 1633-1635.

3. Malaguarnera G, Madeddu R, Latteri S (2018) Anorectal mucosal melanoma. Oncotarget 9: 8785-8800.

4. Longo WE, Vernava AM 3rd, Wade TP, Coplin MA, Virgo KS, et al. (1995) Rare anal canal cancers in the U.S. veteran: patterns of disease and results of treatment. Am Surg 61: 495-500.

5. Hillenbrand A, Barth TF, Henne-Bruns D, Formentini A (2008) Anorectal amelanotic melanoma. Colorectal Dis 10: 612-615.

6. Singer M, Mutch MG (2006) Anal melanoma. Clin Colon Rectal Surg 19: 78-87.

7. Row D, Weiser MR (2009) Anorectal melanoma. Clin Colon Rectal Surg 22: 120-126.

8. Moore WD (1897) Recurrent melanosis of the rectum after previous removal from the verge of the anus in a man aged sixty-five. Lancet 1: 290-294.

9. Iddings DM, Fleisig AJ, Chen SL, Faries MB, Morton DL (2010) Practice patterns and outcomes for anorectal melanoma in the USA, reviewing three decades of treatment: is more extensive surgical resection beneficial in all patients? Ann Surg Oncol 17: 40-44.

10. Adler MJ, White CR Jr (2007) Amelanotic malignant melanoma. Semin Cutan Med Surg 16: 122-130.

11. Pizzichetta MA, Talamini R, Stanganelli I, Puddu P, Bono R, et al. (2004) Amelanotic/ hypomelanotic melanoma: clinical and dermoscopic features. Br J Dermatol 150: 1117 1124. [Crossref]

12. Klemperer P, Rubin CB (1931) Primary neoplasm of the pleura: a report of five cases. Arch Pathol 11: 385-412.

13. Tenna S, Poccia I, Cagli B, Aveta A, Manzo MJ, et al. (2012) A locally aggressive solitary fibrous tumor of the leg: Case report and literature review. Int J Surg Case Rep 3: 177-180. [Crossref]

14. Gold JS, Antonescu CR, Hajdu C, Ferrone CR, Hussain M, et al. (2002) Clinicopathologic correlates of solitary fibrous tumors. Cancer 94: 1057-1068. [Crossref]

15. Voth E, Serio S, Gross J, Singh A, Dietz N, et al. (2018) Solitary fibrous tumor of the stomach with high-grade sarcomatous dedifferentiation. J Surg Case Rep. [Crossref]

16. Fillmann LS, Fillmann EEP, Fillmann HS, de Oliveira JK, Parizotto JFB, et al. (2012) Anorectal melanoma: review of diagnosis and treatment based on a case report. $J$ Coloproctol.

17. Duport C, Tiffet O, Perrot JL, Prévot N, Rey Y, et al. (2006) Sentinel node mapping in anorectal melanoma. Ann Chir 131: 550-552. [Crossref]

18. Olsha O, Mintz A, Gimon Z, Gold Deutch R, Rabin I, et al. (2005) Anal melanoma in the era of sentinel lymph node mapping: a diagnostic and therapeutic challenge. Tech Coloproctol 9: 60-62. [Crossref]
19. Stoidis CN, Spyropoulos BG, Misiakos EP, Fountzilas CK, Paraskeva PP, et al. (2009) Diffuse anorectal melanoma; review of the current diagnostic and treatment aspects based on a case report. World J Surg Oncol 7: 64. [Crossref]

20. Mariolis-Sapsakos T, Malamitsi J, Yakoumakis E, Orfanos F (2008) Is sentinel node mapping useful in anorectal melanoma? Hell J Nucl Med 11: 39-42. [Crossref]

21. Homsi J, Garrett C (2007) Melanoma of the anal canal: a case series. Dis Colon Rectum 50: 1004-1010.

22. Van't Riet M, Giard RW, de Wilt JHW, Vles W (2007) Melanoma of the anus disguised as hemorrhoids: surgical management illustrated by a case report. Dig Dis Sci 52: 17451747.

23. Hossne RS, Prado RG, Neto AB, Junior ED, Ferrari A (2007) Melanoma anorretal: relato de 2 casos e revisão da literatura. Rev bras Coloproct 27: 317-321.

24. Annam V, Panduranga C, Kodandaswamy CR (2008) Primary anorectal malignan melanoma - a case report and review of literature. J Gastrointest Canc 39: 1-3.

25. Slingluff CL, Jr, Vollmer RT, Seigler HF (1990) Anorectal melanoma: Clinical characteristics and results of surgical management in twenty-four patients. Surgery 107: 1-9.

26. Morson BC, Volkstadt H (1963) Malignant melanoma of the anal canal. J Clin Pathol 1: $126-132$.

27. Weyandt GH, Eggert AO, Houf M, Raulf F, Bröcker EB, et al. (2003) Anorectal melanoma: surgical management guidelines according to tumour thickness. $\mathrm{Br} J$ Cancer 89: 2019-2022. [Crossref]

28. Stefanou A, Nalamati SP (2011) Anorectal Melanoma. Clin Colon Rectal Surg 24: 171 176

29. Pernick N (2020) Melanoma. Accessed November 16th, 2020. https://www pathologyoutlines.com/topic/anusmelanoma.html.

30. Longacre TA, Rouse RV (2011) Primary melanoma of the anus. Surgical Pathology Criteria. Stanford University School of Medicine; Original posting/updates.

31. da Cruz GMG, de Souza J, Filho A, Patrus G (2014) Anorectal melanoma histopathological and immunohistochemical features and treatment. J Coloproctol.

32. Chute DJ, Cousar JB, Mills SE (2006) Anorectal malignant melanoma - morphologic and immunohistochemical features. Am J Clin Pathol 126: 93-100.

33. Ishizone S, Koide N, Karasawa F, Akita N, Muranaka F, et al. (2008) Surgical treatment for anorectal malignant melanoma: report of five cases and review of 79 Japanese cases. Int J Colorectal Dis 23: 1257-1262. [Crossref]

34. Wanebo HJ, Woodruff JM, Farr GH, Quan SH (1981) Anorectal melanoma. Cancer 47: 1891-1900.

35. Breslow A (1970) Thickness, cross-sectional areas and depth of invasion in the prognosis of cutaneous melanoma. Ann Surg 172: 902-908.

36. Ross M, Pezzi C, Pezzi T, Hickey R, Balch C (1990) Patterns of failure in anorecta melanoma. A guide to surgical therapy. Arch Surgery 125: 313-316. [Crossref]

37. Thibault C, Sagar P, Nivatvongs S, Ilstrup DM, Wolff BG (1997) Anorectal melanoma - an incurable disease? Dis Colon Rectum 40: 661-668. [Crossref]

38. Moozar KL, Wong CS, Couture J (2003) Anorectal malignant melanoma: treatment with surgery or radiation therapy, or both. Can J Surg 46: 345-349.

39. Kim KB, Eton O, Davis DW, Frazier ML, McConkey DJ, et al. (2008) Phase II tria of imatinib mesylate in patients with metastatic melanoma. Br J Cancer 99: 734-740. [Crossref]

40. Park SH, Kim MJ, Kwon J, Park JP, Park MS, et al. (2007) Solitary fibrous tumor arising from stomach: CT findings. Yonsei Med J 48: 1056-1060. [Crossref]

41. Keraliya AR, Tirumani SH, Shinagare AB, Zaheer A, Ramaiya NH (2016) Solitary fibrous tumors: 2016 imaging update. Radiol Clin North Am 54: 565-579. [Crossref]

42. Robinson LA (2006) Solitary fibrous tumor of the pleura. Cancer Control 13: 264-269.

43. Inayat F, Hussain Q, Shafique K, Hurairah A, Grossman EB (2017) Solitary fibrous tumor of the stomach. ACG Case Rep J 4: e35. [Crossref]

44. 43. Faisal Inayat, Qulsoom Hussain, Khurram Shafique, et al. (2017) Solitary Fibrous Tumor of the Stomach. ACG Case Rep J 4: e35.

45. Park SH, Kim MJ, Kwon J, Park JP, Park MS, et al. (2007) Solitary fibrous tumor arising from stomach: CT findings. Yonsei Med J 48: 1056-1060. [Crossref] 
Marinova L (2020) Complex treatment after pathohistological and immunohistochemical analysis in synchronous neoplasms - anorectal achromatic malignant melanoma and gastric extrapleural solitary fibrous tumor

46. Knösel T, Schulz B, Katenkamp K, Katenkamp D, Petersen I (2010) Solitary fibrous tumor and haemangiopericytoma: what is new? Pathologe 31: 123-128. [Crossref]

47. Tenna S, Poccia I, Cagli B, Aveta A, Manzo MJ, et al. (2012) A locally aggressive solitary fibrous tumor of the leg: Case report and literature review. Int J Surg Case Rep 3: 177-180. [Crossref]

48. Silva GSC, Nunes MB, de Almeida PBG, de Oliveira RM, de Oliveira Guimarães RE, et al. (2014) Solitary fibrous tumor of the kidney: a case report. J Bras Patol Med Lab.

49. Hasegawa T, Matsuno Y, Shimoda T, Hasegawa F, Sano T, et al. (1999) Extrathoracic solitary fibrous tumors: their histological variability and potentially aggressive behavior. Hum Pathol 30: 1464-1473. [Crossref]

50. Nielsen GP, O'Connell JX, Dickersin GR, Rosenberg AE (1997) Solitary fibrous tumor of soft tissue: a report of 15 cases, including 5 malignant examples with light microscopic, immunohistochemical, and ultrastructural data. Mod Pathol 10: 10281037. [Crossref]

51. Stout AP, Murray MR (1942) Hemangiopericytoma: a vascular tumor featuring Zimmermann's pericytes. Ann Surg 116: 26-33.

52. Fukunaga M, Naganuma H, Nikaido T, Harada T, Ushigome S (1997) Extrapleural solitary fibrous tumor: a report of seven cases. Mod Pathol 10: 443-450.

53. Vallat-Decouvelaere AV, Dry SM, Fletcher CD (1998) Atypical and malignant solitary fibrous tumors in extrathoracic locations: evidence of their comparability to intrathoracic tumors. Am J Surg Pathol 22: 1501-1511.

54. Lee JC, Fletcher CD (2011) Malignant fat-forming solitary fibrous tumor (so-called "lipomatous hemangiopericytoma"): Clinicopathologic analysis of 14 cases. Am J Surg Pathol 35: 1177-1185.

55. Baliga M, Flowers R, Heard K, Siddiqi A, Akhtar I (2007) Solitary fibrous tumor of the lung: a case report with study of the aspiration biopsy, histopathology, immunohistochemistry and autopsy findings. Diagn Cytopathol 35: 239-244. [Crossref]

56. Clayton AC, Salomao DR, Keeney G, Nascimento AG (2001) Solitary fibrous tumor of six cases diagnosed by fine-needle aspiration. Diagn Cytopathol 25: 172-176. [Crossref]

57. Parwani AV, Galindo R, Steinberg DM, Zeiger MA, Westra WH, et al. (2003) Solitary fibrous tumor of the thyroid: cytopathologic findings and differential diagnosis. Diagn Cytopathol 28: 213-216. [Crossref]

58. Ali SZ, Hoon V, Hoda S, Heelan R, Zakowski MF (1997) Solitary fibrous tumor. A cytologic-histologic study with clinical, radiologic, and immunohistochemical correlations. Cancer Cytopathol 81: 116-121.

59. Daigeler A, Lehnhardt M, Langer S, Steinstraesser L, Steinau HU, et al. (2006) Clinicopathological findings in a case series of extrathoracic solitary fibrous tumors of soft tissues. BMC Surg. [Crossref]

60. Kinoshita Y, Takasu K, Hosaka N, Omura N, Yuri T, et al. (2013) Solitary extrapleural fibrous tumor of axillary skin diagnosed by fine-needle aspiration cytology, coinciden with simultaneous breast fibroadenoma. World Journal of Medical and Surgical Case Reports.

61. Ide F, Obara K, Mishima K, Saito I, Kusama K (2005) Ultrastructural spectrum of solitary fibrous tumor: a unique perivascular tumor with alternative lines of differentiation. Virchows Arch 446: 646-652. [Crossref]

62. Westra WH, Gerald WL, Rosai J (1994) Solitary fibrous tumor. Consistent CD34 immunoreactivity and occurrence in the orbit. Am J Surg Pathol 18: 992-998.

63. Rovera F, Imbriglio G, Limonta G, Marelli M, La Rosa S, et al. (2008) Solitary fibrous tumor of the male breast: a case report of the literature. World J Surg Oncol 6: 16. [Crossref]

64. Erbag G, Qureshi HS, Patterson JW, Wick MR (2007) Solitary fibrous tumor of the skin: a clinicopathologic study of 10 cases and review of the literature. J Cutan Pathol 34: 844-850. [Crossref]

65. Soldano AC, Meehan SA (2008) Cutaneous solitary fibrous tumor: a case report of 2 cases and review of the literature. Am J Dermatopathol 30: 54-58.

66. Senteusanio G, Schiaroli O, Ortenzi A, Mulè A, Perrone G, et al. (2008) Solitary fibrous tumor of thyroid: report of two cases with immunohistochemical features and literature review. Head and Neck Pathol 2: 231-235. [Crossref]

67. Guillou L, Fletcher JA, Fletcher CDM, Mandahl N (2002) Extrapleural solitary fibrous tumor and haemangiopericytoma. In: Fletcher CDM, Unni KK, Mertens E, editor. World Health Organization Classification of Tumours, Pathology and Genetics of Tumours of Soft Tissue and Bone. Lyon: IARC Press; pp: 86-90.

68. Brunnemann RB, Ro JY, Ordonez NG, Mooney J, El-Naggar AK, et al. (1999) Extrapleural solitary fibrous tumor: a clinicopathologic study of 24 cases. Mod Pathol 12: 1034-1042. [Crossref]
69. Morimitsu Y, Nakajima M, Hisaoka M, Hashimoto H (2000) Extrapleural solitary fibrous tumor: clinicopathologic study of 17 cases and molecular analysis of the p53 pathway. APMIS 108: 617-625. [Crossref]

70. Wang H, Chen P, Zhao W, Shi L, Gu X, et al. (2014) Clinicopathological findings in a case series of abdominopelvic solitary fibrous tumors. Oncol Lett 7: 1067-1072. [Crossref]

71. Gengler C, Guillou L (2006) Solitary fibrous tumour and haemangiopericytoma: Evolution of a concept. Histopathology 48: 63-74.

72. Mentzel T, Bainbridge TC, Katenkamp D (1997) Solitary fibrous tumour: clinicopathological, immunohistochemical, and ultrastructural analysis of 12 cases arising in soft tissues, nasal cavity and nasopharynx, urinary bladder and prostate. Virchows Arch 430: 445-453.

73. Travis WD, Chung A, Aubry MC (2004) Mesenchymal tumours. In: Travis WD Brambilla E, Müller-Hermelink, Harris CC, editor. World Health Organization Classification of Tumours, Pathology and Genetics of Tumours of the Lung, Pleura, Thymus and Heart. Lyon: IARC Press; pp: 141-144.

74. Insabato L, Siano M, Somma A, Gentile R, Santangelo M, et al. (2009) Extrapleural solitary fibrous tumor: A clinicopathologic study of 19 cases. International Journal of Surgical Pathology 17: 250-254. [Crossref]

75. Suster S, Nascimento AG, Miettinen M, Sickel JZ, Moran CA (1995) Solitary fibrou tumors of soft tissues: a clinicopathologic and immunohistochemical study of 12 cases. Am J Surg Pathol 19: 1257-1266. [Crossref]

76. van de Rijn M, Lombard CM, Rouse RV (1994) Expression of CD34 by solitary fibrous tumors of the pleura, mediastinum and lung. Am J Surg Pathol 18: 814-820.

77. Chilosi M, Facchetti F, Dei Tos AP, Lestani M, Morassi ML, et al. (1997) Bcl-2 expression in pleural and extrapleural solitary fibrous tumours. J Pathol 181: 362-367. [Crossref]

78. Hasegawa T, Hirose T, Seki K, Yang P, Sano T (1996) Solitary fibrous tumor of the soft tissue. An immunohistochemical and ultrastructural study. Am J Clin Pathol 106 325-331.

79. Clayton AC, Salomão DR, Keeney GL, Nascimento AG (2001) Solitary fibrous tumor: a study of cytologic features of six cases diagnosed by fine-needle aspiration. Diagn Cytopathol 25: 172-176.

80. Chick JF, Chauhan NR, Madan R (2013) Solitary fibrous tumors of the thorax Nomenclature, epidemiology, radiologic and pathologic findings, differential diagnoses, and management. AJR Am J Roentgenol 200: W238. [Crossref]

81. Ge W, Yu DC, Chen G, Ding YT (2016) Clinical analysis of 47 cases of solitary fibrous tumor. Oncol Lett 12: 2475-2480. [Crossref]

82. Akisue T, Matsumoto K, Kizaki T, Fujita I, Yamamoto T, et al. (2003) Solitary fibrous tumor in the extremity: Case report and review of the literature. Clin Orthop Relat Res 411: 236-244. [Crossref]

83. Chilosi M, Facchetti F, Tos APD, Lestani M, Morassi ML, et al. (1997) Bcl-2 expression in pleural and extrapleural solitary fibrous tumours. J Pathol 181: 362-367. [Crossref]

84. England DM, Hochholzer L, McCarthy MJ (1989) Localized benign and malignant fibrous tumors of the pleura. A clinicopathologic review of 223 cases. Am J Surg Pathol 13: 640-658.

85. Vallat-Decouvelaere AV, Dry SM, Fletcher CD (1998) Atypical and malignant solitary fibrous tumors in extrathoracic locations: evidence of their comparability to intrathoracic tumors. Am J Surg Pathol 22: 1501-1511.

86. Kayani B, Sharma A, Sewell MD, Platinum J, Olivier A, et al. (2018) A review of the surgical management of extrathoracic solitary fibrous tumors. Am J Clin Oncol 41 687-694. [Crossref]

87. Briselli M, Mark EJ, Dickersin GR (1981) Solitary fibrous tumors of the pleura: eight new cases and review of 360 cases in the literature. Cancer 47: 2678-89.

88. Nassif MO, Trabulsi NH, Bullard Dunn KM, Nahal A, Meguerditchian AN (2013) Soft tissue tumors of the anorectum: rare, complex and misunderstood. J Gastrointest Oncol 4: 82-94. [Crossref]

89. de Perrot M, Fischer S, Brundler MA, Sekine Y, Keshavjee S (2002) Solitary fibrous tumors of the pleura. Ann Thorac Surg 74: 285-293. [Crossref]

Copyright: (C)2020 Marinova L. This is an open-access article distributed under the terms of the Creative Commons Attribution License, which permits unrestricted use, distribution, and reproduction in any medium, provided the original author and source are credited. 